\title{
The Emerging Role of Academia in Sqa
}

\author{
Waqas Mahmood \\ Department of Computer Science, Institute of Business Administration, Karachi, Pakistan \\ E-mail:wmehmood@iba.edu.pk
}

\section{Syed Shaharyar Rizvi}

Department of Computer Science, Institute of Business Administration, Karachi, Pakistan

E-mail: s.rizvi.23243@khi.iba.edu.pk

\author{
Siraj Munir \\ Department of Computer Science, Institute of Business Administration, Karachi, Pakistan \\ E-mail: s.munir.23254@khi.iba.edu.pk
}

Received: 10 January 2021; Accepted: 18 March 2021; Published: 08 June 2021

\begin{abstract}
Now that every company and every consumer prioritize quality over quantity of work, the career of Software quality assurance is also taking a leap, especially in the field of academia. Thus, this report gives an overview of what a future with the usage of software quality control and testing would look like, and why it's needed for the development of the caliber of software used all around the globe. It further marks out why adding courses related to software quality assurance in the curriculum is important and how this addition can widen the dynamics of software control, quality and testing industries. It also marks out how, even today, academia can and is playing an integral role in the developmental process of software quality assurance and testing in terms of the research that can be and is being made towards the whole developmental process of SQA. Universities and undergraduate programs can further play an important role towards the researching the horizons and fields software testing and assurance has to offer in the near future. Furthermore, this report questioned various practitioners belonging to some of the most prestigious IT companies about their opinion on the research questions involved in this report so as to verify the credibility of the data that has been gathered. At the end of the research, we have a foresight for as to how the industry of software quality assurance and software testing will grow.
\end{abstract}

Index Terms: Software testing, Academia, Software Engineering, Software Testing Skills, Need of Software Industry in QA \& Testing, SDLC: Software Development Life Cycle, Software Testing Life Cycle

\section{Introduction}

Nowadays with the increasing competition, every software company wants to produce high-quality products. To produce such quality, they hire those people who have good analytical and programming skills who can solve their complex problems with their code. [1]

Unfortunately, most of the graduates enter their professional careers with strong development skills, but lack proficiency in the area of software testing and debugging to write good quality code because in most universities there is not any specialized course related to Software Quality Assurance in their academic curriculum. [2] The majority of the time, they teach some initial levels of SDLC, like requirements gathering, algorithm design, and its implementation missing the ignorant, yet the most important part called Software Testing. [2]

Though they have a lot to offer so why not adapt testing and techniques to boost up their career in no time. Educational Institutes must take necessary measures in providing relevant courses as a part of curricula so that the graduate ace in all the aspects of what computer science is all about. [3]

The courses related to software quality education must be introduced with relevant experienced mentors with proficiencies in Test Planning, Design, and Execution, and those who have expertise in Test automation using different techniques like $\mathrm{CI} / \mathrm{CD}$, etc. [4]

\section{a. Research Purpose}

Our goal is to make such a relatable thing that can leave an impact on the importance of QA hence minimizing the gap between academia and industry. 


\section{Background}

As software systems are growing in size and complexity, testing these complex systems is becoming more difficult. There are various tools available that make software developers more productive but there is very little emphasis on testing tools that can help Testers in increasing their productivity. [2]

The lack of formal education related to software quality assurance and testing at the undergrad level forcing industries to spend more money to train those graduates in the art of software testing which includes how to test/break any system or how to find the corner cases of any app. [2]

The Software Quality Assurance Engineer role is gaining importance by leaps and bounds and it is growing at the uniqueness of its own. Because, nowadays, even after the project/product development ends and the software is deployed to the production level, we need the QA resource who can test and monitor that system even after the delivery. $[3,4]$

There were many major accidents that were caused because no proper testing was done on that system. For example, in 1997, there was a plane crash of flight 747 of the Korean Airline in which 200 people lost their lives caused by faulty software, similarly there were many other incidents which have been witnessed in the past caused by faulty software because proper investments and efforts were not made on testing of these systems. [2]

In general, there is a lack of research and development specific to the area of software quality and testing, as foreseen in other areas of software engineering, which now needs to overcome. [5]

\section{Literature Review}

Now that the emergence of software quality assurance has been normalized, the importance of academia-industry collab in the areas of software engineering have been boosted too, workshops and panels are internationally organized on a pretty regular basis, where apart from highlighting the importance of IAC, successful collaborations are discussed and celebrated. Further gaps are bridged between this prestigious collaboration as one of the main motives of such panels. [3]

An increased need for industry-academia collaboration is demanded when the topic of System engineering is brought up, Practitioners have been engaged in surveying the relevance of SE in research. When the survey was studied, it was shown how the practitioners had found no tallying relations between the connected scores of the papers and the citation counts. [1]

Furthermore, the study also identified reasons as to why the experienced practitioners thought of some selected research ideas as irrelevant and disconnected. Later on, in a study about making software engineering relevant it was shown how practitioners didn't usually prefer reading academic articles and rather chose books, blogs, and forums over the mentioned medium. It was highlighted how it was important to have a fresh mindset in order to make researches more relevant and applicable in terms of Software Engineering. The idea of software quality assurance and research relevance has been proposed in order to meet a better and fresh phase of Software Engineering researches. [3]

\section{a. Future of SQA in academia}

On the off chance that the field of software engineering is to be held with a similar exactness and a similar meticulousness as the other designing fields, then a ton load more effort has to go into its software testing and its quality assurance, the Software Quality Assurance has to be treated like the software's basic need. Further on in this review on literature, software testing is evaluated as a profession, keeping in mind the survey of the recent curriculum guidelines and a survey-based idea of testing of education, in a more practical approach. [2]

Professional approach; Software testing: Software testing as a profession today, is on the hike, everyone working under the name of "software programmers" or computer software engineers" have spent at least little percentage of the time executing software-testing roles. A more practical approach to the profession marks out the fact that as the agile methods of development (which are test-based) will rise and become more relevant in the software engineering practices, there will be a hand in hand rise in software graduates ending up in the software testing roles in a more professional and identified capacity. Software testing will be normalized, later in the future and to reap the fruit it bears, one should be able to keep up with it and its practices. [6, 7]

\section{b. Publications under Software Testing}

There exist a few publications aiming specific at the processes of software-testing considering its slow and steady growth. But, the only thing closest to a paper dedicated to software and its testing is the "International Symposium on Software Testing and Analysis" that comes under the dedicated ACM special interest group. [3]

Right now, there seems to be lacking professional organizations running dedicatedly for sole purpose of softwaretesting, but like it was stated before, once the use of test-based methods of development is normalized, the growth of software testers and software quality assurance tools will come quickly too. [8] 
Publications remain the best means to convey best practices and innovative fresh ideas for the field and it is to be remembered that it is difficult for academia to shapen and strengthen their curriculum and guidelines denying such an important medium. [8]

\section{Research Methodology}

This section presents the methodologies and techniques which will be used to conduct this research.

\section{a. Research Questions (RQs) and Goals}

To address the study and survey, we will analyze by checking the curriculums of the top-ranked universities of the country, which are mostly available online. We will try to analyze which University's Computer Science offers Software Quality Assurance as a core course or its related courses and which universities are least bothered about it. [2]

Our goal of this study is to find the challenges and the gap which is observed by Industry professional while hiring or working with fresh Software QA \& Test Engineers. [8]

This study aims to inform academia or universities about the real problems faced by industry.

In contrast to the above goal, we have adopted similar research questions from one of the research papers and also, added our own research question as well related to niche market these days. [6,9]

RQ1: Do you think that Universities should include courses related to Software Quality \& Testing as a compulsory course in their curriculum?

RQ2: Do you think that courses related to SQA should be taught by industry practitioners?

RQ3: What challenges does industry experience when each type of testing activity is performed by some junior team member? [3]

RQ4: As testing industry dynamics are changing day by day, so is it important to add Automation testing as a part of the curriculum?

\section{b. Research Method}

In contrast to above mentioned research questions, we will conduct an online survey gathering responses from industry practitioners and seeking help from "Survey guidelines in Software Engineering". [10] We will also rely on our relations and experiences in conducting online surveys through google forms.

Since industry practitioners participated in that survey, we tried to keep the minimum number of questions so that it would take less time to fill the survey and, in this way, we will be able to get a higher number of responses.

The questionnaire has Seven questions, in which the first 2-3 questions were about their basic info like Name, Designation, and Organization to ensure the accuracy and authenticity of data. Then the remaining questions were MCQ's based on which RQ1, RQ2, \& RQ4 are based on Yes/No question which will give the overall feedback of the industry practitioners about the inclusion of compulsory Software testing related courses in the curriculum and who should teach those courses. In RQ3, we asked for the challenges the industry face when a fresh or junior level resource who just joined the industry after graduation performs some testing activities. To answer this question, we provided the list of some testing activities which are mentioned and provided the scale based on of 1 to 6 . [3, 7, 11]

$1=$ No Challenges $6=$ Lots of challenges (Academia should focus to teach these skills)

After discussion with some senior testing practitioners, we prepared the following list of Eight testing activities which are normally performed on routine basis. These are following:
1. Test Case Design
2. Test scripting
3. Test execution
4. Test evaluation
5. Test results/bug reporting [12]
6. Test management
7. Test automation

\section{Results}

We present the results by providing the data of practitioner's designations and from which IT Companies they belong (it will be categorized as 'Demographics') followed by the results of research questions. More than 90 people have participated in this survey till now.

\section{a. Demographics}

The 1st three questions were asked about their personal information like from which company they belong and what's their current designation. The purpose of these question was to verify the credibility of the data we are gathering. 
Figure 1. shows the number of participants belongs to different organizations in Pakistan. We gathered data from some of the most reputed software companies based in Pakistan including 10Pearls, Systems Limited, Airlift, Gaditek, and many others.

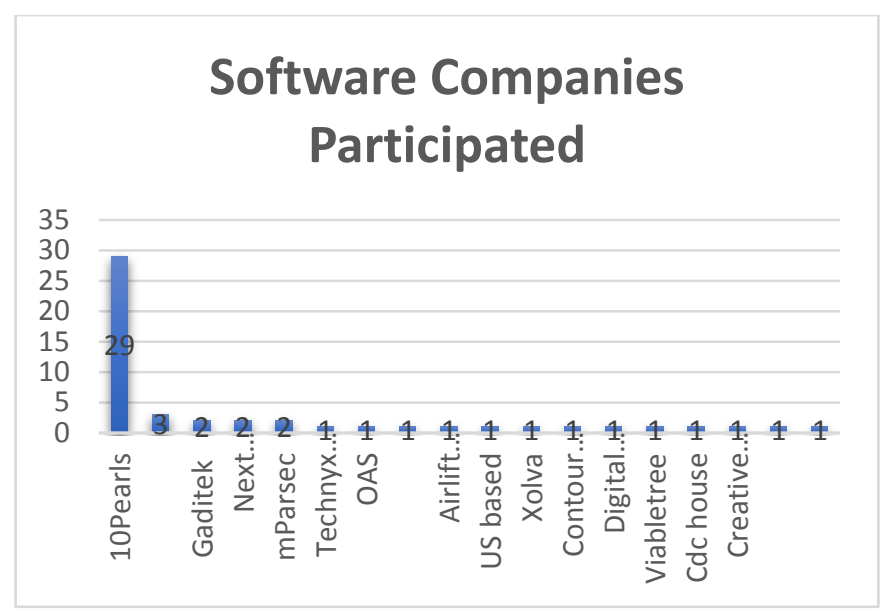

Fig.1.Break down of dataset by Software House

Figure 2. shows the designation of the people who participated in the above-mentioned software companies. Most of the participants are working as Software Quality Assurance engineers on different seniority levels and some Project Managers, Directors Software Services, and Software Engineers also participated in this survey.

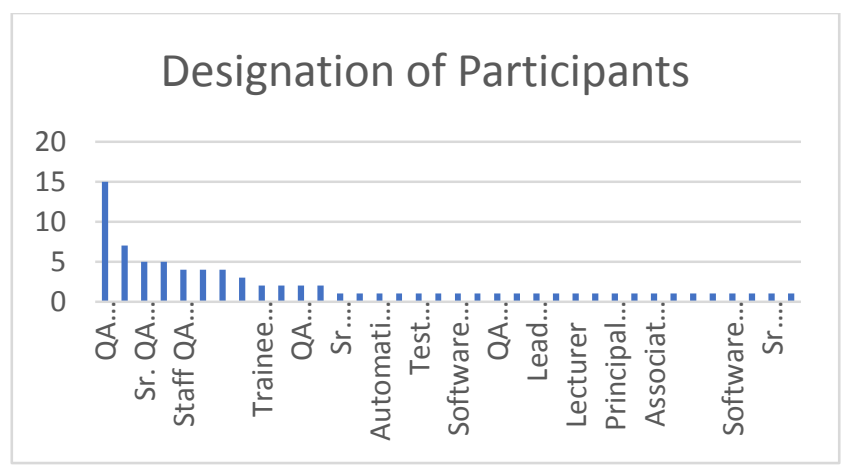

Fig.2. shows the Designation of Participants.

b. RQ1: Should Universities include courses related to Software Quality \& Testing as a compulsory course in their curriculum?

Figure 3. shows the result in the form of Pie chart in which $92 \%$ of participants think that Universities should include Software Testing related courses as a compulsory course in their curriculum of Computer Science or Software Engineering degree.

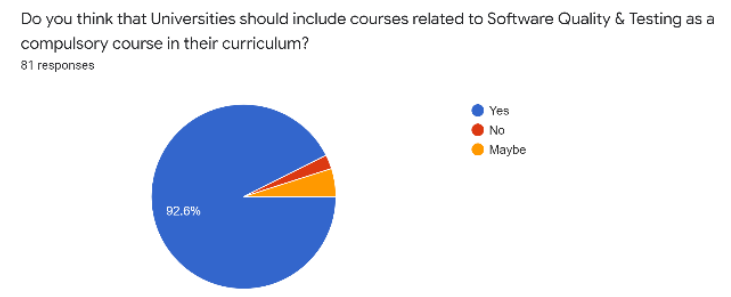

Fig.3. show the results of RQ1

c. RQ2: Is courses related to Software Testing be taught by industry practitioners?

Figure 4. shows the result in Pie Chart form in which $86 \%$ of participants think that these courses should be taught by Industry Practitioners so that students can get hands-on experience on different tools and techniques which will be useful for them while working in the industry. 


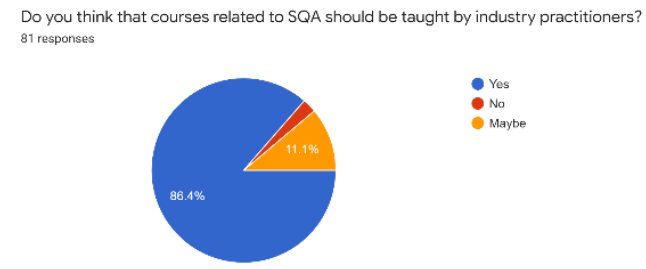

Fig.4. show the results of RQ2

d. RQ3: What challenges does industry experience when each type of testing activity is performed by some junior team member?

Figure 5. represents the result of one of the main questions of our survey, in that questions participants were given different options to select based on the given testing activities which are mentioned previously in Research methodology.

In basic level tasks like Test Case Design, Scripting, and Execution, the industry faces fewer challenges and junior QA resources are able to perform them flawlessly. But in the activities like Test Evaluation, Bug reporting, practitioners faced more challenges and most participants reported that Automation testing is a highly challenging thing for Junior level resources.

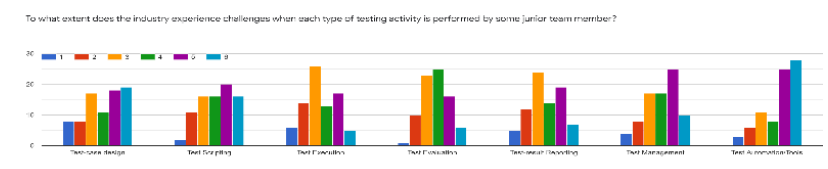

Fig.5. Histogram result of RQ3

e. RQ4: Is it important to add Automation testing as a part of the curriculum?

Figure 6. shows the result in Pie Chart form in which $85 \%$ of the participants think that courses related to Automation testing should be a part of the curriculum. These days Automation testing is the most demanding skill in the current job market and more people want to automate the testing of their products to save the money and time to go production time. We can teach different topics and tool/practices/frameworks which are being used in the current market.

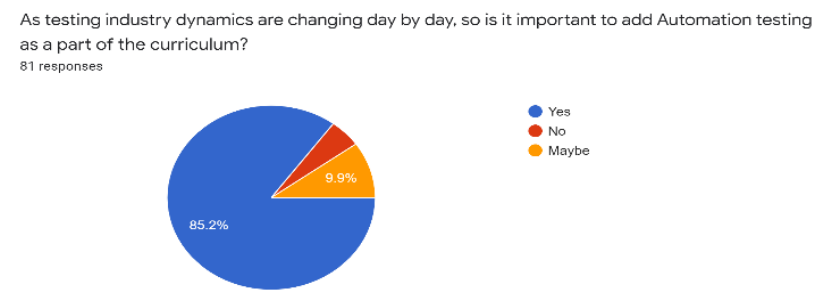

Fig.6. show the results of RQ2

\section{Comparative Analysis}

The section describes the comparison of one of the Research Questions i.e., RQ3 which we opted from other similar papers. [3] That question discussed the different levels of challenges faced by industries when some Testing activities are performed by a junior team member. There were 8 different activities were given in that survey question and practitioners had to rate on a scale of 1 to 6 in which 1 stand for 'No Challenge is faced by them' whereas 6 means that industry is facing lots of challenges in this type of activity and academia should focus to teach these skills.

So, we compared our results with the results that were taken in the similar research that was conducted in different regions like Canada, Turkey, Denmark, Austria [3] and found out that their results were similar to our survey results in which most of the participants belong to Pakistan region.

Both results reported that they faced Little or No challenge faced when some basic level activities are done by these team members like Test Case design, Test Execution, Bug reporting, etc. But in activities like Test management, Test Scripting, or Automating those manual tests these members are highly challenged because of a lack of knowledge 
about the tools, and industries need to invest their time and money to train these resources in those skills which they are lacking. [13]

\section{Conclusions and Future Work}

The research examined the emerging role of Software Quality Assurance in academia and the future that it holds in the field of Software Engineering. [3] It further created a picture, based on the research questions proposed in this research, of expectations that the companies in Pakistan hold about the future of testing and software quality assurance in as a profession, and positive results pointing towards the growth of this industry were seen. [8] Demographics showed in this report mark out the results of the research questions. This research further marked out the need for reformation of the curriculum to make it inclusive of software testing and quality assuring skills to make undergraduates and graduates better equipped for future opportunities.

We also put forward the fact as to how software testing is an agile method of development and how it is on the rise and might be one of the biggest deals in the near future, so keeping up with the works of SQA would be a wise move, not just for the end-users, but also the companies and the country in the long term. [5] A lot more work has to be put into this industry for it to grow and the current track and the wish to grow sounds promising to the industry and thus should be kept up.

Future work includes:

- Continue collecting practitioners' perceptions about trends of software testing in the field of Automated testing. [1]

- Reasons for lack of focus on SQA in the public sector as well as private sector Universities in Pakistan imparting computer science and software engineering education.

\section{References}

[1] V. S. Raluca Florea, "The skills that employers look for in software testers," Software Quality Journal (2019) Springer Science, Business Media, LLC, August 2019.

[2] E. M. D. ,. C. L. R. P. M. R. W. Tara Astigarraga, "The Emerging Role of Software Testing in Curricula," IBM Systems and Technology Group, 2010.

[3] M. M. K. H. VahidGarousi, "What industry wants from academia in soware testing," EASE'17, 2016.

[4] Altexsoft, "QA Engineering Roles: Skills, Tools, and Responsibilities in a Testing Team," 24 May 2020. [Online]. Available: https://www.altexsoft.com/blog/engineering/qa-engineering-roles-skills-tools-and-responsibilities-within-a-testing-team/. [Accessed 5 Nov 2020].

[5] M. M. E. a. K. H. V. Garousi, "Industry-academia collaborations in software testing: experience and success stories from Canada," Software Quality Journal , p. https://doi.org/10.1007/, 2016.

[6] R. v. S. a. E. Berghout, The Goal/Question/Metric Method: A Practical Guide for Quality Improvement of Software Development, Mcgraw-Hill, 1999.

[7] N. N. a. T. Z. D. Lo, "How Practitioners Perceive the Relevance of Software Engineering Research," in Proc. 10th Joint Meeting Foundations of Software Eng. (ESEC/FSE 15), 2015.

[8] V. G. a. M. Felderer, "A comparison of industry and academia focus areas of Software Testing," 2017.

[9] E. W. Dijkstra, "On the cruelty of really teaching computing science," Unpublished, 1988.

[10] S. M. S. M. H. Johan Lin aker, Guidelines for Conducting Surveys in Software, Sweden: Software Engineering Research Group, June, 2015.

[11] J. H. O. h. D.I.K. Sjoeberg, "A survey of controlled experiments in software engineering," IEEE Transactions on Software Engineering, vol. 31, p. 9, 2005.

[12] S. T. Help, "How To Write A Good Bug Report? Tips And Tricks," December 2020. [Online]. Available: https://www.softwaretestinghelp.com/how-to-write-good-bug-report/\#more-102.

[13] K. Walk, "How to Write a Comparative Analysis | Writing Center at Harvard University," 1998. [Online]. Available: https://writingcenter.fas.harvard.edu/pages/how-write-comparative-analysis. [Accessed 27 Dec 2020].

[14] A. M. A. B.-C. a. S. M. V. Garousi, " A systematic mapping study of web application testing," 2013.

[15] P. O. S. B. I. R. a. J. N. S. Beecham, "Making Software Engineering Research Relevant. Computer 47, 4," 2014.

[16] P. A. a. J. Offutt, Introduction to Software Testing (2 ed.), 9781107172012, 2016.

[17] N. J. a. D. M. O. Dieste, "Software Industry Experiments: A Systematic Literature Review," in Proceedings of the 1st International Workshop on Conducting Empirical Studies in Industry, Madrid, 2013.

[18] K. P. P. M. S. S Ravichandran, "Software Quality Assurance (SQA) : Current and Emerging Trends," Intelligent Electronic Systems, vol. 1, p. 31, November 2007.

[19] R. F. Viktoria Stray, "A Global View on the Hard Skills and Testing Tools in Software Testing," in ACM/IEEE 14th International Conference on Global Software Engineering (ICGSE), May 2019.

[20] V. S. Raluca Florea, "Software Tester, We Want to Hire You! an Analysis of the Demand for Soft Skills," in Agile Processes in Software Engineering and Extreme Programming, May 2018, pp. 54-67.

[21] K. P. Paloli Mohammed Shareef, "Software Quality Assurance (SQA): Current and Emerging Trends," International Journal on Intelligent Electronic Systems ISSN 0973-9238, p. 5, 2007. 
[22] R. v. S. a. E. berghout, The Goal/Question/Metric Method: A Practical Guide for Quality Improvement of Software Development., London: The McGaw-Hill Companies ISBN 007 709553 7, 1999.

[23] A. T. a. R. Kazman., "On the Worthiness of Software Engineering," 2017.

[24] P. R. M. H. M. C. O. B. R. a. A. W. C. Wohlin, "Experimentation in Software Engineering," Springer, 2012.

[25] T. A. D. Library, "There Are 349,140 Software Testers in the U.S.," 2009. [Online]. Available: https://www.daniweb.com/hardware-and-software/microsoft-windows/news/219885/there-are-349-140-software-testers-in-theu-s\#post975934. [Accessed December 2020].

[26] D. Sjoeberg, J. Hannay, O. Hansen, V. Kampenes, A. Karahasanovic, N.-K. Liborg and A. Rekdal, "A survey of controlled experiments in software engineering," 03 October 2005. [Online]. Available: https://ieeexplore.ieee.org/document/1514443. [Accessed Dec 2020].

[27] R. K. Antony Tang, "On the Worthiness of Software Engineering Research," [Online]. Available: https://shidler.hawaii.edu/sites/shidler.hawaii.edu/files/users/kazman/se_research_worthiness.pdf. [Accessed 13 December 2020].

[28] C. R. P. H. M. O. M. R. B. W. A. Wohlin, "Experimentation in Software Engineering," Springer, 2012.

[29] C. Wohlin, "Software Engineering Research Under the Lamppost," ICSOFT 2013, 2013.

[30] J. S. N. A. A. B. June M. Verner, "Guidelines for industrially-based multiple case studies in software engineering," in Research Challenges in Information Science, 2009. RCIS 2009., 2009.

[31] S. T. O. S. M. T. K. H. H. F. E. A. O. B. V. Garousi, "Automated Testing of Simulation Software in the Aviation Industry: An Experience Report," IEEE Software, 2019.

\section{Authors' Profiles}

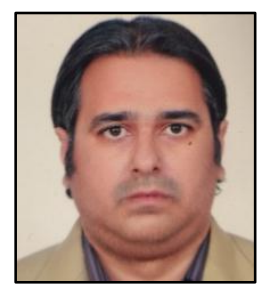

Waqas Mahmood has done Masters in Economics and Finance from Institute of Business Management (IoBM), in 2012. He also holds a degree of Masters in Software Project Management from National University of Computer \& Emerging Sciences - FAST. He has also completed M. Engg from Hamdard University and M.E from NED University, Karachi. His Bachelor's was completed in 1998 from Sir Syed University of Engineering \& Technology, Karachi. He is currently working as Joint Director in State Bank of Pakistan since January 2008. In IBA, He's serving as visiting faculty for last 10 years.

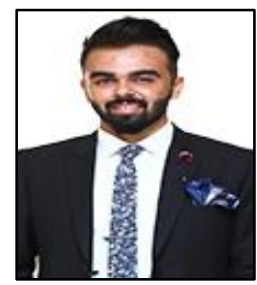

Syed Shaharyar Rizvi is a Tech-Functional Consultant by Profession currently working at InfoTech Group. He got his BS degree in Computer Sciences from DSU, Karachi and is currently perusing MS Degree for the IBA, Karachi.

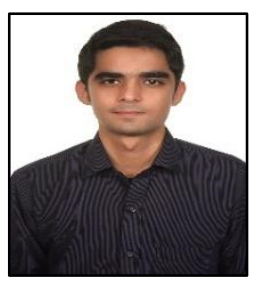

Siraj Munir is a Test Automation Engineer by Profession currently working at 10 Pearls. He got his BS degree in Computer Sciences from DSU, Karachi and is currently perusing MS Degree for the IBA, Karachi.

How to cite this paper: Waqas Mahmood, Syed Shaharyar Rizvi, Siraj Munir, " The Emerging Role of Academia in Sqa ", International Journal of Engineering and Manufacturing (IJEM), Vol.11, No.3, pp. 28-34, 2021. DOI: 10.5815/ijem.2021.03.03 